\title{
ON THE BLOOD LACTIC ACID RESPONSE TO MEASURED EXERCISE IN HYPOXIC HUMAN SUBJECTS ${ }^{1}$
}

\author{
BY JAY TEPPERMAN ${ }^{2}$ AND HELEN M. TEPPERMAN 2 \\ WITH THE TECHNICAL ASSISTANCE OF BARBARA W. PATTON \\ (From the Yale Aeromedical Unit, Department of Physiology, Yale University School of \\ Medicine, New Haven)
}

(Received for publication September 13, 1947)

When working mammalian muscle tissue is deprived of sufficient oxygen to support oxidative metabolism at a specified work load, lactic acid accumulates in the muscle cells, diffuses into the extracellular fluid and thence into the circulating blood. That the concentration of lactate in the circulating blood is a true indication of tissue lactate concentration in working muscle has been shown by Newman (1). Thus, it is theoretically possible to test the adequacy of a continuing supply of oxygen to working muscle by measuring changes that occur in blood lactate concentration following measured bouts of exercise.

According to the hypothesis of Bang (2), who made extensive studies of the blood lactate response to exercise at sea level barometric pressure, all of the lactic acid formation by muscle during the transition from the resting to the working state occurs before the circulatory and respiratory responses of the organism have collaborated in delivering oxygen to the muscle at the rate required by its work load. When the intricate pattern of reflexes brought into play by the exercise have resulted in hyperpnea, increased cardiac output and local vasodilation in the working muscle, and when oxygen is delivered at a sufficiently rapid rate to support contraction aerobically, lactic acid production practically ceases. Thus, in a subject exercising at a constant rate, Bang (2) found identical blood lactate curves when the work was continued for 10,15 , or 30 minutes.

During the performance of muscular work the organism must make circulatory and respiratory

\footnotetext{
1 This work was done under contract between the Office of Scientific Research and Development and Yale University. The material was originally submitted to the Committee on Aviation Medicine as two reports dated December 1, 1943, and June 27, 1944, respectively.

2 Present address : Department of Pharmacology, Syracuse University College of Medicine, Syracuse, N. Y.
}

adjustments which are qualitatively similar to those made during adaptation to hypoxia. A combination of these stresses, therefore, makes possible the detection of comparatively mild degrees of hypoxia. Edwards (3), in Peru, had demonstrated that non-acclimatized subjects showed unusually high blood lactate levels following the performance of measured work at altitudes of about 9,000 feet and above. Broussilovsky (4), in Kiev, reported similar findings in subjects exposed to simulated altitudes of about 9,000 feet and above in a decompression chamber.

The following report is divided into two sections: the first includes a description of the chemical changes in the blood produced by exercise at low barometric pressure, together with an inquiry into the effect of antecedent muscular training on the response; the second is an account of certain experiments designed to elucidate the mechanism of the response.

\section{METHODS}

Preparation of subjects. All experiments, including sea level control runs, were done in the decompression chamber at $70^{\circ} \pm 2^{\circ} \mathrm{F}$. The subjects sat at rest for at least one hour before the first blood sample was taken; experiments were begun between two and one-half and four hours after the preceding meal, usually breakfast. When repeated studies were made on the same individual an effort was made to duplicate experimental conditions, especially with respect to composition and time of the last meal, length of rest period, time of day, and activity involved in coming to the laboratory.

Visible sweating was largely avoided by having the subjects wear athletic shorts or playsuits, and by providing an adequate amount of ventilation at all times.

Work load. In the preliminary experiments standingrunning to a metronome was first used as the standard exercise. However, it was soon found that this is an unreliable method of assigning reproducible exercise loads. Therefore, the subjects were instructed to do deep kneebends in time to a metronome at the rate of 30 per minute. On six occasions this amount of exercise proved to have distressing after-effects; five of the subjects complained 
of extreme stiffness of the lower extremities and weakness of the knees, persisting, in some cases, for as long as eight days. One of the subjects was hospitalized two days after he exercised at 15,000 feet when it was found that he had moderately severe "hemoglobinuria." $\mathrm{He}$ made a satisfactory recovery, however, in about three days.

In the second series of experiments measured amounts of work were performed on an eddy-current brake cycle ergometer, kindly loaned by Professor E. C. Schneider of Wesleyan University. The instrument was calibrated in kilogram-meters of work per minute at a pedal speed of 60 pedal revolutions per minute, the subject pedalling in time to a metronome mounted between the handle-bars. Almost all of the subjects were able to check themselves within two or three pedal revolutions for three-minute exercise periods after very little training. They were instructed to use their upper extremities as little as possible during the performance of work.

Blood studies. Heparinized arm-vein blood was used in all experiments. In the ergometer experiments an electrically heated gauntlet was placed on the arm about five minutes before each blood sample was to be drawn. While not as effective as immersing the hand in hot water, this procedure causes a vasodilation of the vessels of the hand, increased blood flow, and diminished arteriovenous differences. Incidentally, it also facilitates the Derformance of ten venepunctures in two hours in subjects whose veins are not prominent.

Protein precipitation was carried out in the chamber. Trichloracetic acid filtrates for lactate and pyruvate estimations were made within two minutes after the blood was drawn. Lactate was estimated by means of the Evelyn photoelectric colorimeter according to the method of Barker and Summerson (5), and pyruvate, according to the Bueding and Wortis (6) modification of the method of Lu. The glucose method was that of Somogyi (Peters and Van Slyke [7]), and amino acid nitrogen analyses were performed by the technique of Frame, Russell and Wilhelmi (8). Arterial oxygen saturation was estimated by the oximeter method of Millikan (9).

I. A DESCRIPTION OF THE CHEMICAL CHANGES IN THE BLOOD FOLLOWING EXERCISE AT LOW BAROMETRIC PRESSURE

\section{A. Preliminary experiments}

The initial experimental design required each subject to perform two short bouts of exercise (deep knee-bends) separated by a 72-minute period of sitting at rest. Blood samples were taken just before, and 5, 15, 30 and 45 minutes after the beginning of each bout. In seven of the nine subjects who did two successive bursts of exercise at sea level, the second burst resulted in a smaller lactate rise than the first. In the other two, the curves were the same.
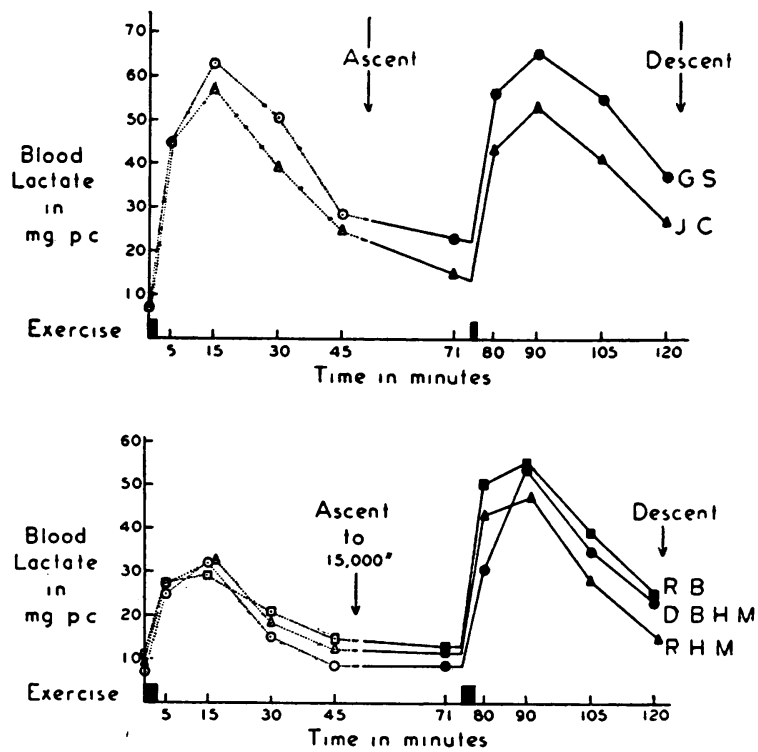

Fig. 1. Effect of Exercise at Sea Level Followed by Exercise at 15,000 Feet in Two Poorly Trained Subjects (G. S. and J. C.) and Three Well-Trained Subjects (R. B., D. B. H. M. ANd R. H. M.)

Two young men, both in a poor state of athletic training, exercised to capacity for two minutes at sea level, ascended to 15,000 feet about 45 minutes later, and began to exercise at altitude 75 minutes after the beginning of the first exercise period. The results of these experiments are plotted in Figure 1. Although the duration of exercise in each case was cut from two minutes to one minute and 20 seconds, the configurations of the blood lactate curves at altitude closely resembled those of the sea level curves.

Typical responses of three well-trained athletes are shown in Figure 1. Similar results were obtained in a total of nine experiments on seven subjects. It is apparent that the blood lactate following exercise at 15,000 feet is much higher than it is following the same amount of exercise at sea level. However, since, as has already been stated, the second of two serial bouts of exercise often results in a smaller lactate rise than the first, this experiment does not afford a satisfactory method of comparing performance at altitude and at sea level.

\section{B. Ergometer experiments}

Six subjects volunteered to serve for a series of three or four experiments. Two of the men 

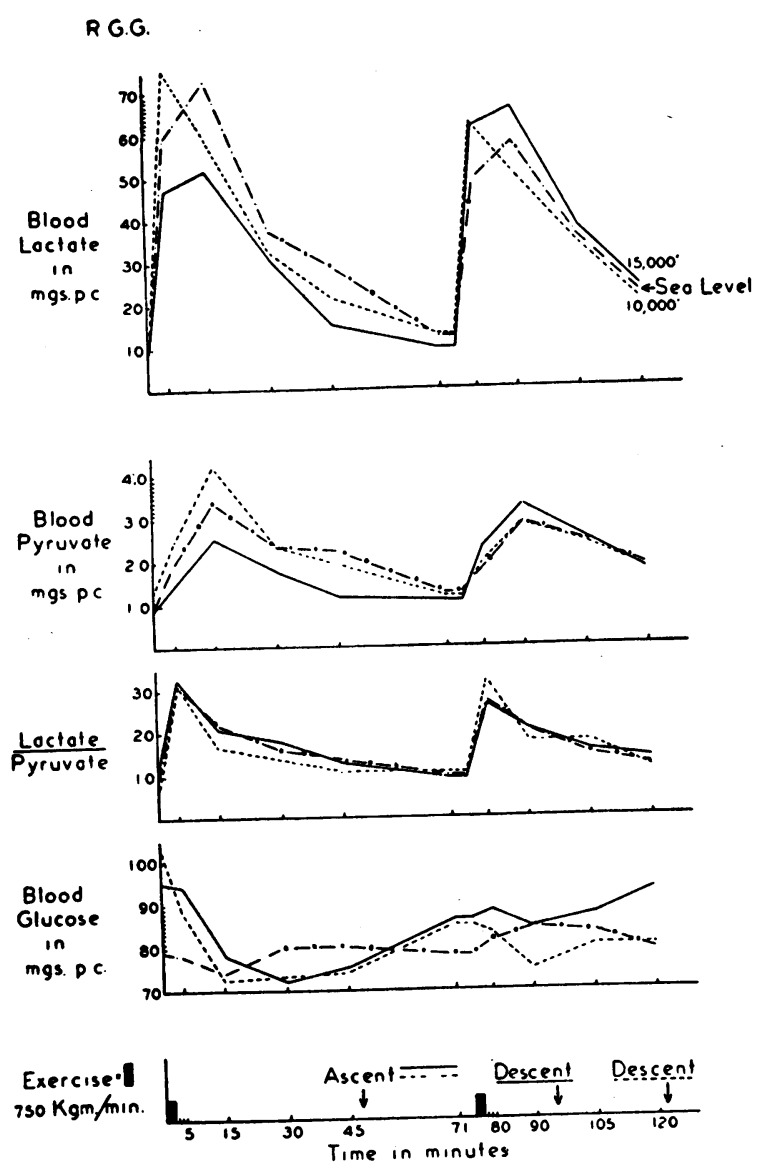

Fig. 2. Subject R. G. G. Poorly Trained Male, Age 27, ht. 5'10", wt. 170 LbS. Exercise: Cycle ERgometer

Both exercise bouts at sea level, 8/12/43. Second exercise bout at 10,000 feet, $9 / 2 / 43$. . Second exercise bout at 15,000 feet, $9 / 22 / 43$.

were in poor athletic training and had not ridden a bicycle since early boyhood. The other four were well-trained cyclists who often rode from 5 to 15 miles per day. Two of these were arbitrarily assigned heavy work loads, whereas the other two were given moderate ones. The general experimental plan was similar to that used in the preliminary experiments, with the exception that all comparisons of performance at different simulated altitudes were done on the second of the two exercise periods. Thus, each subject exercised once at sea level before doing the critical part of the experiment for each day. This procedure was adopted because it was believed that the second of two consecutive tests would be more likely to produce uniform responses than the first. In retrospect, the blood lactate responses of the four trained subjects showed rather remarkable internal consistency of performance from one test day to another, even after the first of the two exercise periods.

In addition to lactate and glucose, the pyruvate and amino acid nitrogen content of whole blood were estimated, the volume of packed red blood cells was measured, and the oxygen saturation of the arterial blood was estimated by means of the Millikan oximeter. Pulse rates were counted before and after each exercise bout and after recovery. The results of these experiments are presented graphically in Figures 2 to 6 . Since the
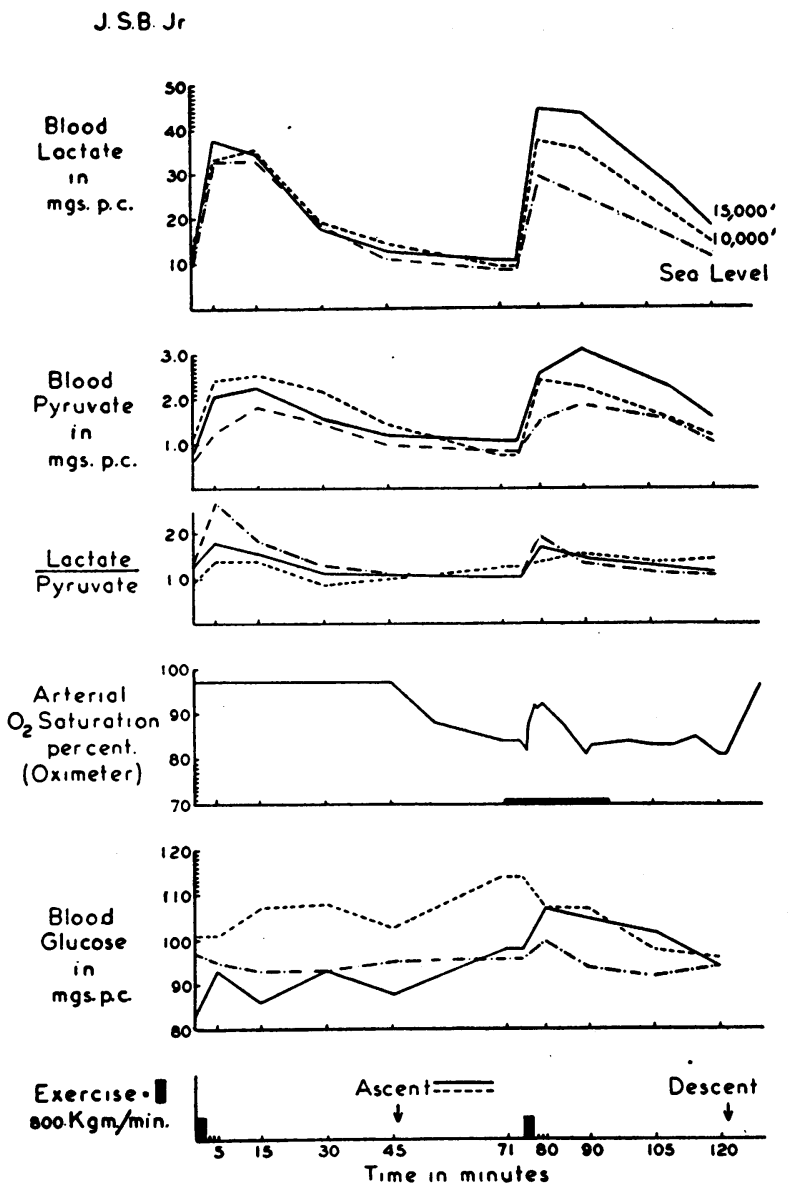

Fig. 3. Subject J. S. B. Jr. Male, Age 25, ht. 5'10", wt. 138 las. Well-Trained Cyclist. Exercise: CyCle ERgometer

Both exercise bouts at sea level, 9/13/43. Second exercise bout at 10,000 feet, $8 / 16 / 43$. Second exercise bout at 15,000 feet, $8 / 30 / 43$. 
findings in the two untrained subjects, the two trained subjects working at a moderate work load and the two trained subjects working at a heavy work load all showed remarkably close agreement within each pair, the complete experimental record of only one individual in each category will be presented.

Blood lactate. Untrained subject R. G. G. (Figure 2) showed large increases in blood lactate

\section{R.S.S.W.}
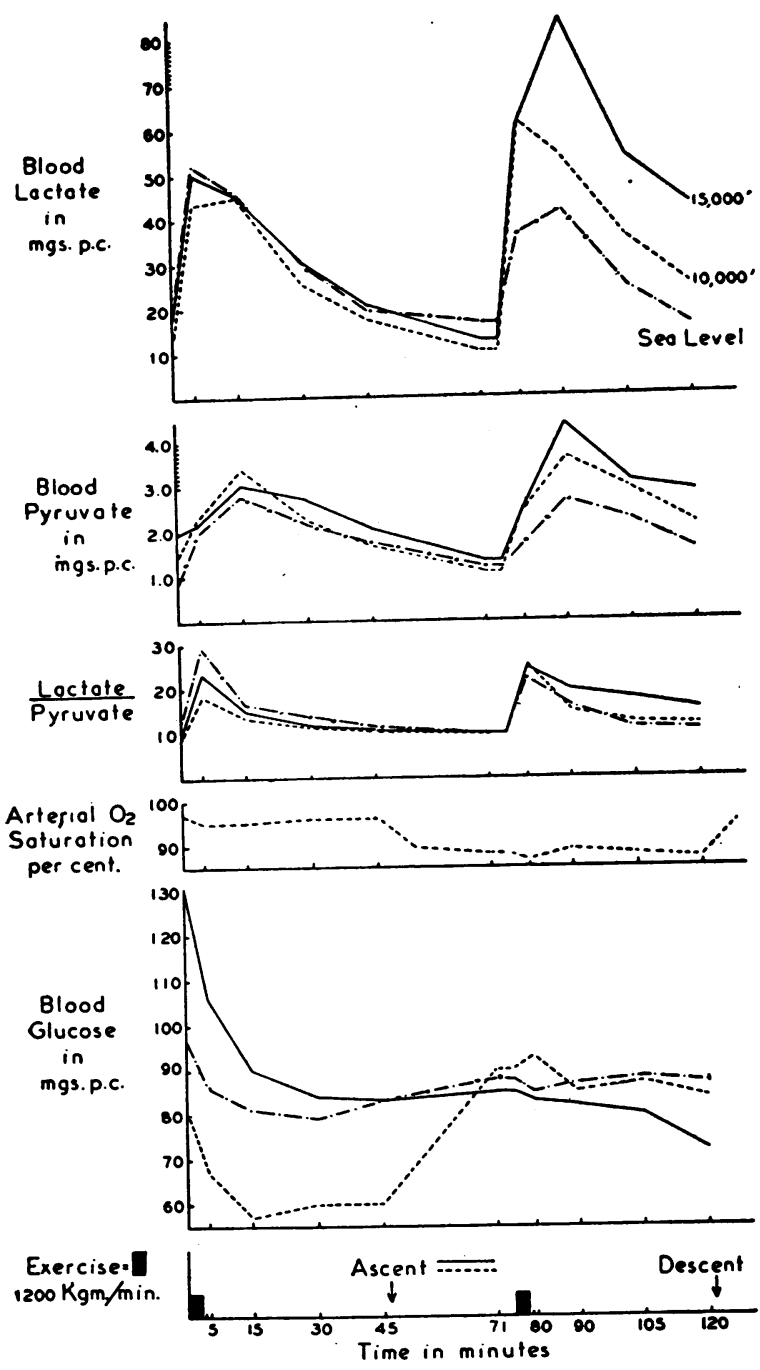

Fig. 4. Subject R. S. S. W. Male, Age 28, ht. 5'11", wt. 155 lbs. Well-Trained Cyclist. Exercise: Cycle Ergometer

Both exercise bouts at sea level, 9/10/43. Second exercise bout at 10,000 feet, $8 / 27 / 43$. Second exercise bout at 15,000 feet, $9 / 22 / 43$.
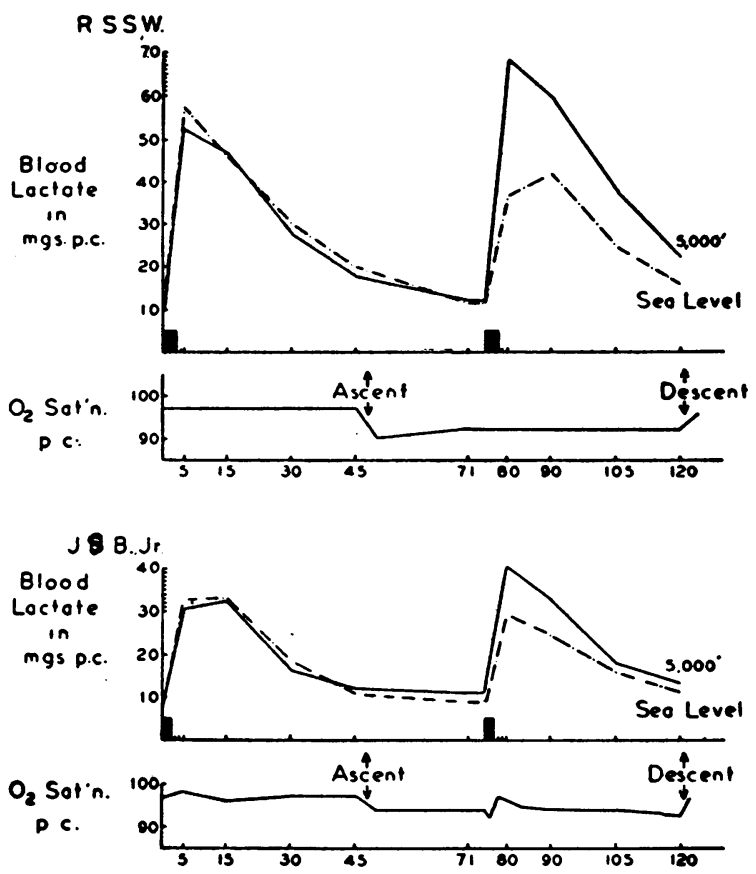

Fig. 5. Effect of Exposure to 5,000 Feet on Blood Lactate Responses of Two Well-Trained Subjects

R. S. S. W., 10/13/43. J. S. B. Jr., 10/21/43. For details of previous experiments on these subjects, see Figures 3 and 4 , respectively.

after performing a comparatively small amount of work-750 $\mathrm{kgm} . / \mathrm{min}$. for three minutes. Moreover, no valid comparison may be made between his performance at altitude and at sea level, for an examination of the three curves following his initial exercise bout on each of the test days shows that his record lacks consistency. Whether or not the variability in his response is in part due to training effects cannot be stated with certainty. Although the differences in his blood lactate curves at different altitudes are insignificant, this subject was unable to adapt satisfactorily to a simulated altitude of 15,000 feet, for he was forced by impending syncope to descend to sea level about 18 minutes after his bout of exercise at altitude.

The trained subjects (J. S. B. Jr. and R. S. S. W., Figures 3 and 4, respectively) show a remarkably consistent set of lactate curves following the initial bout of exercise and unequivocal differences in response at different altitudes. A comparison of the record of R. S. S. W. (Figure 4) with that of J. S. B. Jr. (Figure 3) shows that the differences between lactate curves at altitude and 

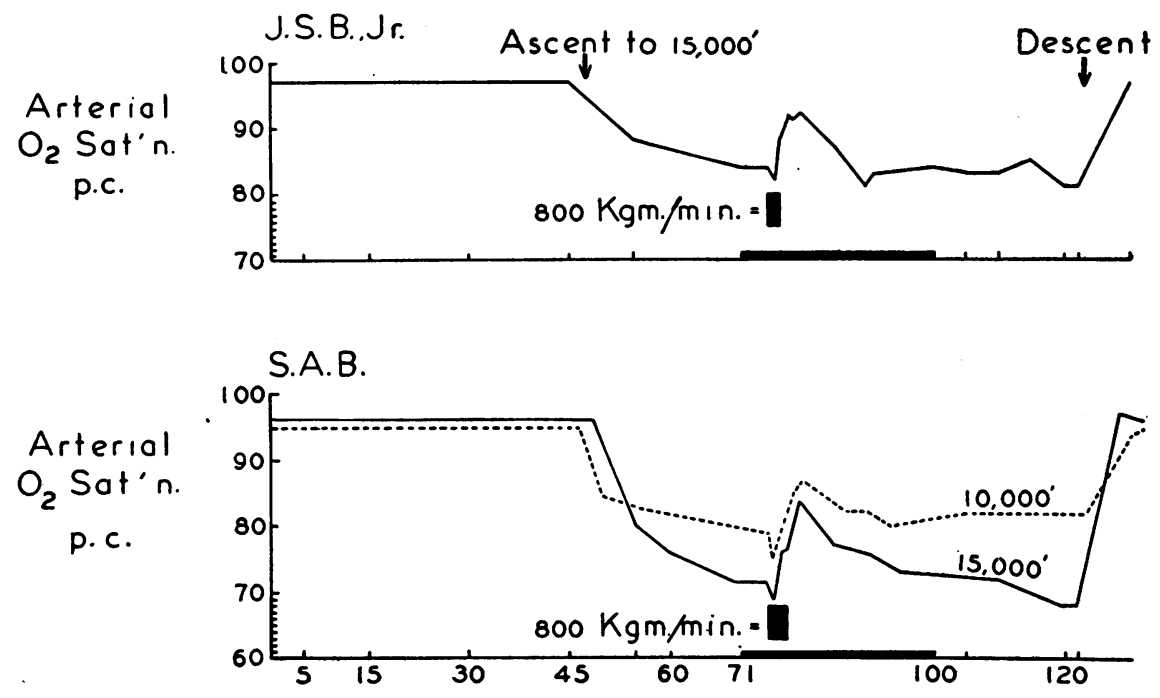

Fig. 6. Effect of Exercise upon the Arterial Oxygen Saturation of Two Subjects at Altitude

Oximeter readings were taken every 10 seconds during time indicated by black bar on time scale.

at sea level are more striking when heavier work loads are done. Presumably this phenomenon has a work-load extinction point since resting blood levels are nearly the same at 15,000 feet as they are at sea level. However, work loads of less than $750 \mathrm{kgm} . / \mathrm{min}$. were not used in this series of experiments.

Three well-trained subjects showed unmistakable upward displacement of the blood lactate curves following exercise at 5,000 feet (Figure $5)$. In all three cases the patterns of response were very similar to those which had previously been observed in the 10,000-feet experiments. Elevated blood lactate curves were accompanied by corresponding changes in the blood pyruvate levels and in the pulse rates following exercise.

Blood pyruvate. In general, the blood pyruvate curves were similar to the homologous blood lactate curves of the individual subjects. Training effects were apparent in the poorly trained subjects and a quite definite stratification was observed at the different altitudes in the four welltrained subjects. However, the pyruvate changes on different occasions at sea level did not show the same degree of consistency found in the corresponding lactate curves, and the pyruvate contrasts with varying degrees of anoxia were not as sharp as were those of the concurrent blood lactate patterns. It must be emphasized here that the method of $\mathrm{Lu}$ was designed to determine alpha keto acids as pyruvate, and that fluctuations in the levels of alpha keto acids other than pyruvate may conceivably occur under the conditions of those experiments. In any case, pyruvate undoubtedly constitutes all but a small portion of the keto acids estimated.

In confirmation of the reports of other investigators, it was found that the peak of the pyruvate curve almost invariably occurred about 15 minutes after the beginning of the exercise period, whereas the truncated configuration of the lactate curves suggests that their peaks occurred most often at about the tenth minute. Since it has been found by Bueding and Goldfarb (10) that the injection of salts of lactic acid results in an appreciable rise in blood pyruvate, the delayed pyruvate peak may be an expression of the re-oxidation of accumulated lactic acid to pyruvic acid.

The lactate-pyruvate ratio was suggested as an index of anoxia by Friedemann (11). This ratio has its greatest significance when it is determined at the time of maximal anoxia, and it is of some interest that the peak values for the ratio were almost invariably observed to occur five minutes 
after the beginning of exercise. Although the ratio of lactate to pyruvate remained high throughout the experiment in three of the four well-trained subjects at 15,000 feet, curves of the ratio do not show the orderly arrangements characteristic of the lactate curves, nor do they correlate well with the state of athletic training of the individual subjects.

Arterial oxygen saturation. Arterial oxygen saturation was estimated by means of the Millikan oximeter. At saturations between 70 per cent and 85 per cent it was found that the galvanometer frequently oscillated slowly over a range of as much as 10 per cent. In such cases the mean deflection was used as the basis of the graphic records in Figures 3 to 5.

There was a noteworthy variation in the degree of arterial unsaturation produced in different subjects by the same degree of reduction in atmospheric pressure. For example, the estimated arterial saturation of J. S. B. Jr. at 15,000 feet was about the same as that of S. A. B. at 10,000 feet.

On five separate occasions definite upward displacement of the blood lactate curve was observed in individuals whose arterial saturation (as estimated by the oximeter) was 90 per cent or above. During two of these experiments readings were rarely below 94 per cent. This is arresting in view of the frequently made statement that symptoms of anoxia are not detectable in human subjects whose arterial oxygen saturation remains above 90 per cent.

The oximeter records of J. S. B. Jr. and S. A. B. afford an opportunity to study the arterial oxygen saturation during exercise. In these experiments oximeter readings were taken every ten seconds during and after exercise. All of the records show a small initial fall in saturation, followed by a rise over the starting level, the peak occurring about five minutes after the beginning of exercise. Subsequently, there is a return to the resting level (See Figure 6).

Blood glucose. Blood glucose concentrations following exercise at sea level and under varying degrees of anoxia were extremely variable. Often exercise was accompanied by a moderate degree of hypoglycemia; but almost as often, the bout of exercise was followed by a small rise in blood sugar. The bizarre patterns described by the variations in blood glucose concentration were in
TABLE I

Effect of hypoxia on pulse rise following measured exercise

Chemical data for these subjects are given in Figures 2 to 4 .

\begin{tabular}{c|c|c|c|c}
\hline \hline Subject & Altitude & $\begin{array}{c}\text { Before } \\
\text { exercise }\end{array}$ & $\begin{array}{c}\text { Pulse } \\
\text { min. after } \\
\text { exercise }\end{array}$ & $\begin{array}{c}45 \text { min. } \\
\text { after } \\
\text { exercise }\end{array}$ \\
\hline R. G. G. & $\begin{array}{c}\text { Sea level } \\
10,000^{\prime}\end{array}$ & 92 & 100 & 90 \\
& $15,000^{\prime}$ & 90 & 120 & 88 \\
& & 150 & 90 \\
J. S. B. Jr. & Sea level & 74 & 122 & 74 \\
& $10,000^{\prime}$ & 96 & 130 & 94 \\
& $15,000^{\prime}$ & 86 & 140 & 94 \\
R. S. S. W. & Sea level & 72 & 128 & 68 \\
& $10,000^{\prime}$ & 66 & 136 & 70 \\
& $15,000^{\prime}$ & 74 & 158 & 88 \\
\hline
\end{tabular}

marked contrast to the orderly profiles of the blood lactate curves.

Amino acid nitrogen and hematocrit. Amino acid nitrogen analyses were performed on the acid tungstate filtrates that were used for glucose analysis. It was found that variations in the blood amino acid nitrogen were very small, and that no increase in the concentration of this blood constituent occurred at 15,000 feet.

The very small apparent rises in amino acid nitrogen frequently seen after exercise may be related to the hemoconcentration which is almost invariably seen following a burst of muscular work, for the ratio of amino acid nitrogen in red cells and plasma has been found in this laboratory to be about 3.2 to 1 . The hemoconcentration of exercise has been studied by Keys and Taylor (12), who regard it as true hemoconcentration, and not the result of an increased number of circulating red blood cells. It is of some interest that hemoconcentration at altitude did not appear to be greater, or of longer duration, than it was at sea level.

Pulse. The pulse rate immediately after exercise at altitude was higher than it was at sea level. In the four trained subjects the maximal pulse rates varied directly with the maximal lactate concentrations in 11 out of 12 experiments (see Table I).

\section{STUDIES RELATING TO THE MECHANISM OF THE BLOOD LACTATE RESPONSE TO EXERCISE AT LOW BAROMETRIC PRESSURE}

Bang (2) concluded that the predominant factor in the accumulation of lactate in the blood was 
overproduction of lactic acid by comparatively anaerobic working muscle during the first few minutes of exercise. It is postulated here that the differences in lactate accumulation after measured exercise at sea level and at 15,000 feet may also be related to events that occur during the transition from rest to work, rather than to any serious impairment of the oxidative removal of lactate from the blood. This section is devoted to a description of the results of three experiments which tend to support this hypothesis.

\section{A. A comparison of the disappearance rate of lactate at sea level and at 15,000 feet}

A comparison of the disappearance rates of lactate after exercise at sea level and at 15,000 feet was not considered feasible because the peak concentration of lactate at 15,000 feet was frequently twice that at sea level. In the case of subjects who did amounts of work comparable to those done by P. T. and DeW. B. in the present study, the difference in lactate concentration at sea level and at 15,000 feet at the summits of the respective curves was 30 to 50 mgs. per cent. It is well known that the rate at which many substances disappear from the blood is in part dependent upon their initial concentration. It was therefore necessary to design an experiment to compare lactate disappearance at sea level and at 15,000 feet; that is to say, an experiment in which the starting lactate levels would be as nearly alike as possible.

At first, it was thought that this could be accomplished by injecting the same amount of a lactic acid salt on two occasions, once at sea level and once at 15,000 feet, and determining the disappearance rates under the two conditions. Accordingly, subject J. L. G. was given 16.4 gms. of racemic Sodium Lactate (Lilly) in $960 \mathrm{cc}$. of water over a period of 21 minutes. As the subject received the last of the infusion the chamber was decompressed to a simulated altitude of 15,000 feet at the rate of 5,000 feet per minute. After four minutes at 15,000 feet the subject suddenly became quite pale, said he "felt funny," and promptly lost consciousness. After a period of apnea lasting about 10 seconds, 10 per cent carbon dioxide in 90 per cent oxygen was administered by oxygen mask and respirations were resumed almost immediately. When he regained consciousness after about 45 seconds, the subject was very pale and his pulse was rapid and thready. The experiment was therefore terminated. It is suggested that syncope in this case was due to the additive effects of hyperventilation alkalosis superimposed on a pre-existing, and probably, progressively developing, sodium lactate alkalosis. In view of the evident risk involved, this experimental approach was discarded.

Another technique of securing identical starting levels of blood lactate was adopted. In addition to dispensing with an intravenous infusion, this method had the advantage of introducing the natural isomer of lactic acid into the blood, rather than a racemic mixture. The subject exercised for three minutes on the cycle ergometer at sea level and the blood lactate curve at sea level was followed over a period of 60 minutes. On another day, under as nearly the same conditions as possible, he performed the same amount of exercise at sea level, remaining at sea level fór 9 minutes. Between 9 and 12 minutes after the beginning of the exercise bout the chamber was decompressed to a simulated altitude of 15,000 feet, and the recovery curve was determined at that altitude during the subsequent 48 minutes, the 10 -minute sample having been obtained during decompression. Two such experiments were completed; the results are presented graphically in Figure 7. Subject P. T., who was a highly trained athlete whose day to day lactate response curves to the same work load were practically identical, showed almost no difference in lactate or pyruvate disappearance rates at the two altitudes. Poorlytrained subject DeW. B., however, showed a slightly slower rate of disappearance of both lactate and pyruvate at 15,000 feet than at sea level. Other sea level control curves on the latter subject, however, deviated from each other by 2 to 5 mgs. per cent, which tends to detract from the significance of the difference found here.

B. Effect of breathing 100 per cent oxygen on blood lactate and pyruvate responses to exercise at sea level

A comparison was made of the contour of the blood lactate and pyruvate responses to measured exercise in a well-trained subject, P. T., who breathed 100 per cent oxygen during exercise on 

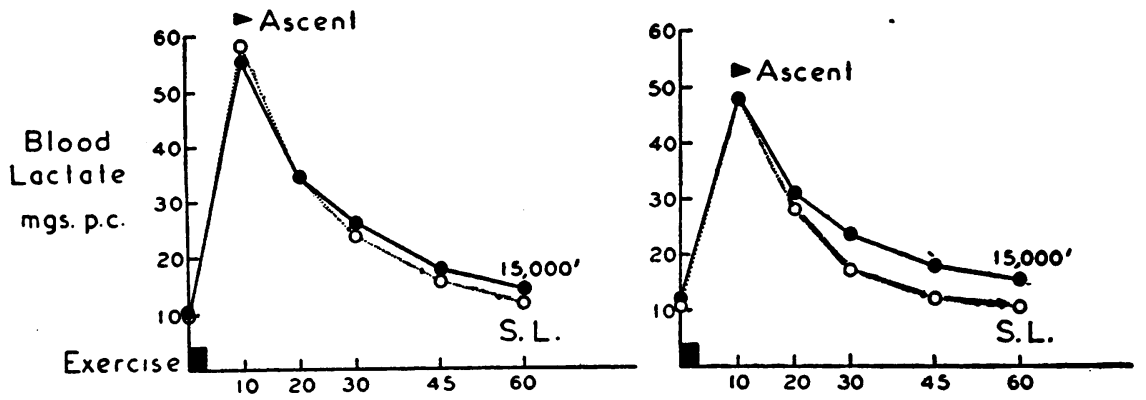

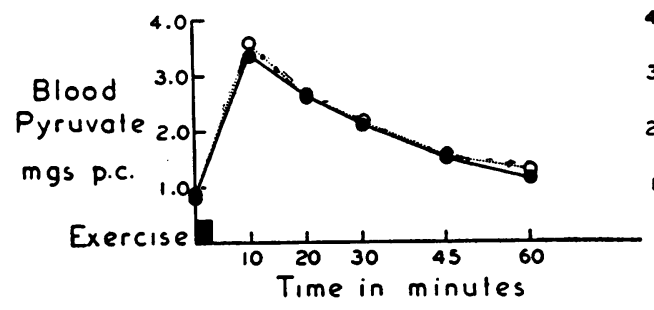

Subjecl P. I.

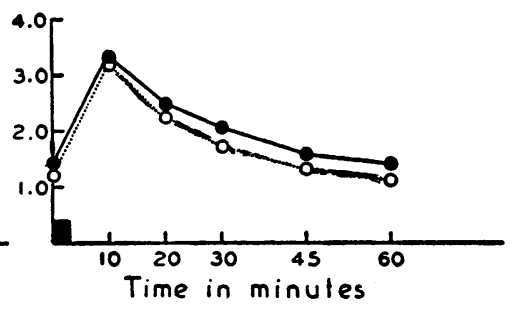

Subjecl DeW. B.

Fig. 7. Lactate Disappearance at 15,000 Feet and at Sea Level

Subject $P$. T., well-trained. Subject DeW. B., poorly trained. On the day marked 15,000 feet the chamber was decompressed to that altitude between the 9th and 12th minutes of elapsed time.

one occasion. This subject performed so consistently that blood lactate curves obtained on five different occasions at the same work load were almost precisely superimposable. Figure 8 shows the effect of breathing 100 per cent oxygen during exercise, and room air during recovery. The maximum deviation from the control curve is about $8 \mathrm{mgs}$. per cent, which, in the case of this subject, is regarded as highly significant.

Similar experiments were done on two other subjects, DeW. B. and J. T., but the results were inconclusive. These subjects were in poor athletic training, and it was found that the blood lactate and pyruvate responses to standard exercise during oxygen breathing were not significantly different from the rather variable responses of these subjects obtained during air breathing.

\section{Effect of intravenous infusion of glucose on blood lactate and pyruvate at sea level and at 15,000 feet}

Another type of experiment was designed to evaluate the importance of the exercise bout as compared with the recovery period in the lactate response to exercise at altitude. It is well known that ingestion or injection of glucose is followed by transitory elevation of the lactic and pyruvic acid concentrations of the blood of many species (for example, see Bueding and Goldfarb, [10]). If the rate of removal of lactic acid from the blood is an important determinant of the contour of the lactate curve at altitude, it was suggested that glucose infusion at altitude might result in a higher and longer sustained lactacidemia than at sea level. That this is not the case is shown by the following experiments.

Subjects J. L. G. and E. P. were studied as follows : 100 gms. of glucose in $700 \mathrm{cc}$. of water were given intravenously over a period of about $20 \mathrm{~min}$ utes. On one day, a sea level control experiment was performed; on another day, the chamber was decompressed to a simulated altitude of 15,000 feet at the end of the infusion. Periodic blood samples were taken during the two hours following the termination of the infusion and the subject was observed. Blood glucose, lactate, and pyruvate were estimated. Experiments on the same subject were separated by three days, and, in 

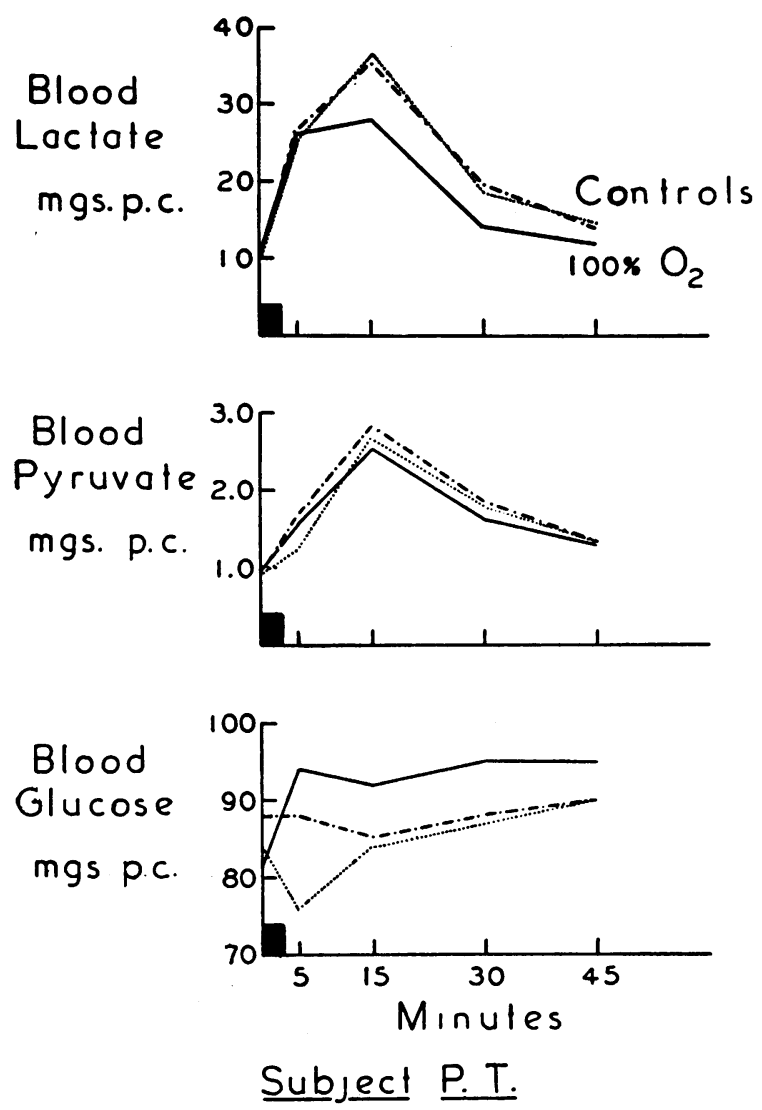

Fig. 8. Effect of Breathing 100 Per Cent Oxygen on Blood Lactate Response to Measured Exercise in a Well-Trained Subject

Oxygen was administered only during the three-minute exercise bout.

the case of J. L. G., the experiment at altitude was carried out before the sea level control study, whereas this order was reversed in the experiments on $\mathrm{E}$. P.

The results are given graphically in Figure 9. It is immediately apparent that the order of magnitude of the rise in lactate and pyruvate provoked by the glucose infusion is the same at 15,000 feet as at sea level; in both instances the change in lactate is of about the same extent as that found by Bueding and Goldfarb (10) in their sea level experiments; namely, about $10 \mathrm{mgs}$. per cent.

The blood glucose in both subjects achieved levels of $550 \mathrm{mgs}$. per cent or more when the estimation was made on samples taken ten minutes after the end of the infusion. In each subject, a definite hypoglycemic reaction (paresthesias, sweating, palpitations, faintness and hunger) occurred at about 90 minutes in the 15,000 -feet experiment. E. P.'s blood glucose shortly after the onset of his hypoglycemic reaction was about 65 mgs. per cent; in J. L. G. the corresponding value was about $60 \mathrm{mgs}$. per cent. The former subject experienced a similar reaction during the sea level experiment, but it occurred about 30 minutes later than it did at altitude. J. L. G. had no hypoglycemic episode during the sea level experiment.

\section{DISCUSSION}

The results of the experiments on subjects in a poor state of athletic training suggest that, as Robinson and Harmon (13) have indicated, each individual has a certain maximum capacity for accumulating lactic acid in the blood. The muscles of the untrained subjects can be regarded as having been so hypoxic at sea level that lowering the arterial oxygen saturation produced no evident additional embarrassment. In the case of the two untrained individuals who did deep knee bends (Figure 1), approximately the same amount of lactic acid was accumulated at 15,000 feet as at sea level, although one-third less work was done in the former experiment.

The well-trained individuals worked well within their respective capacities. The complex series of responses that occur when such an individual begins to exercise were operating at such a high level of efficiency that arterial oxygen saturation was revealed as a limiting factor in the transition from work to rest. Thus, comparatively small changes . in that parameter were reflected in easily measurable differences in lactate accumulation.

The fact that a second bout of exercise at sea level regularly results in a smaller lactate rise than the first suggests the occurrence of a short-term adaptation reminiscent of the Staub-Traugott effect seen following the administration of repeated doses of glucose. The lactate response may be regarded as an expression of the total response of the organism to the change from the resting to the working state. This response includes intracellular components which are related to the actual conversion of chemical into contractile energy, and a complex of reactions that occur outside of the muscle cells, including the respiratory 

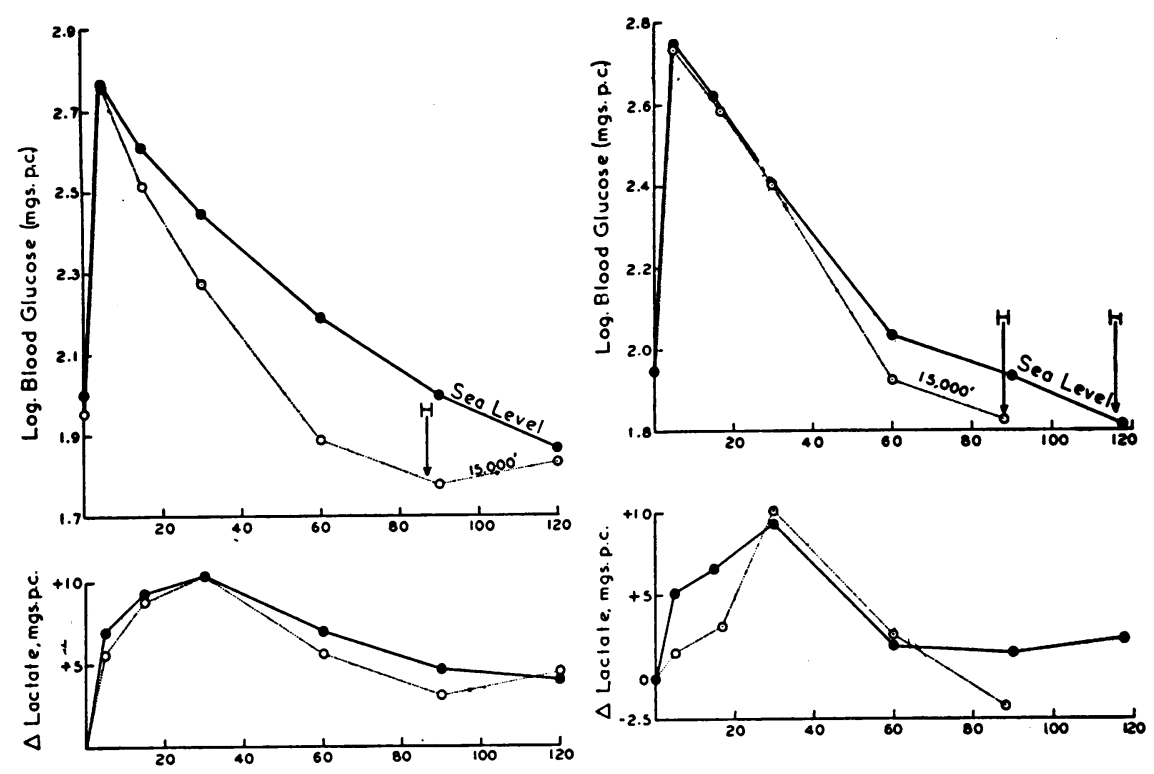

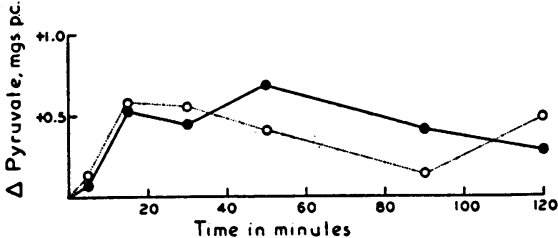

Subjecl LL.G.

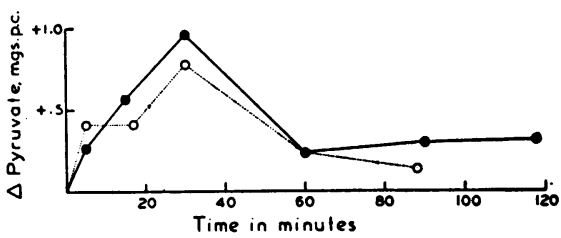

Subjecl E.P.

Fig. 9. Effect of Glucose Infusion on Blood Lactate and Pyruvate at 15,000 Feet and at Sea Level

"H" signifies hypoglycemic episodes.

and cardiovascular reflexes that are initiated by the beginning of exercise. Both intramuscular and extramuscular events may be involved in the fact that the muscle, having recently performed a bout of exercise, begins its second bout with an apparent advantage.

Failure of lactate/pyruvate ratios to correlate with the degree of anoxia in working subjects is in agreement with the findings of Bay and his colleagues (14). These workers state that decrease of blood pyruvate does not truly picture return to aerobic conditions since the disappearance of pyruvate may be due to a variety of reactions, including condensation. From the data presented here it can only be inferred that increases in pyruvate concentrations, within the limits of the greater error involved in measuring smaller amounts of material, are approximately proportional to corresponding increases in lactate concentration.
That impairment of lactate removal is not a significant factor in the upward displacement of the lactate exercise response curve is suggested by the three types of experiment designed to analyze this point. On the basis of the experiments reported here it would have been impossible to demonstrate such an impairment at 5,000 or 10,000 feet. Yet, at those altitudes upward displacement of the blood lactate curve after measured exercise occurred in three individuals. That the exercise period is critical in this displacement is indicated by the fact that there is no significant elevation of the lactate curve when it is produced by a technique not involving exercise; i.e., by glucose infusion. Added to these arguments is the fact that breathing 100 per cent oxygen during the threeminute exercise period produced a clearcut suppression of the lactate response curve in one highly trained athlete.

After these experiments were conducted an op- 
portunity arose for demonstrating a practical application of the lactate response test in another circumstance, anemic anoxia. When the feasibility was considered by the Chemical Warfare Service of protecting men prophylactically against cyanide poisoning by inducing methemoglobinemia, it was necessary to study the effect of methemoglobinemia upon human performance. It was shown by means of the exercise-lactate test (15) that sufficient methemoglobinemia to provide moderate protection against cyanide intoxication produced a definite impairment of oxygenation of human muscle working at moderately heavy work loads.

\section{SUM MARY}

The lactic acid concentration of the blood after measured exercise was higher at low barometric pressure than at sea level pressure. Upward displacement of the lactate curve was found at a simulated altitude as low as 5,000 feet in three welltrained subjects.

Two subjects in a poor state of athletic training . did not show the same orderly, progressive elevation of lactate response curves with increasing hypoxia demonstrated in four well-trained subjects.

In addition to changes in lactate concentration, fluctuations in pyruvate, glucose and amino acid nitrogen concentrations, and in hematocrit, arterial oxygen saturation and pulse rate are described.

From studies on the rate of disappearance of lactate from the blood stream at low barometric pressure and at sea level; on breathing 100 per cent oxygen during exercise ; and on the blood lactate rise at altitude following glucose infusion, it is concluded that overproduction of lactate during exercise is the critical determinant of the response described above. Interference with the mechanisms involved in the removal of lactate from the bloodstream does not contribute significantly to the lactate response at the simulated altitudes studied.

\section{ACKNOWLEDGMENT}

The authors are grateful to Drs. John F. Fulton, Leslie F. Nims and Robert W. Clarke for their help and encouragement, to Delafield DuBois and John Marshall for able assistance, and to the 21 individuals who served as experimental subjects in the course of this study.

\section{BIBLIOGRAPHY}

1. Newman, E. V., Distribution of lactic acid between blood and muscle of rats. Am. J. Physiol., 1938, 122, 359.

2. Bang, O., The lactate content of the blood during and after muscular exercise in man. Skandinav. Arch. f. Physiol., 1936, 74, supplement 10, 49.

3. Edwards, H. T., Lactic acid in rest and work at high altitude. Am. J. Physiol., 1936, 116, 367.

4. Broussilovsky, D., Comportement de l'acide lactique chez des sujets accomplissant un exercise de courte durée à un pression atmospherique diminué. (French summary.) J. Med. de l'acad. des Sc. de la R S S d'Ukraine (Kiev), 1937, 7, 67.

5. Barker, S. B., and Summerson, W. H., The colorimetric determination of lactic acid in biological material. J. Biol. Chem., 1941, 138, 535.

6. Bueding, E., and Wortis, H., The stabilization and determination of pyruvic acid in the blood. J. Biol. Chem., 1940, 133, 585.

7. Peters, J. P., and Van Slyke, D. D., Quantitative Clinical Chemistry. Vol. II. Methods, p. 469. Williams and Wilkins Co., Baltimore, 1946.

8. Frame, E. G., Russell, J. A., and Wilhelmi, A. E., The colorimetric estimation of amino nitrogen in the blood. J. Biol. Chem., 1943, 149, 255.

9. Millikan, G. A., Oximeter, instrument for measuring continuously oxygen saturation of arterial blood in man. Rev. Scient. Instruments, 1942, 13, 434.

10. Bueding, E., and Goldfarb, W., Blood changes following glucose, lactate, and pyruvate. injections in man. J. Biol. Chem., 1943, 147, 33.

11. Friedemann, T. E., and Barborka, C. J., The significance of the ratio of lactic to pyruvic acid in the blood after exercise. J. Biol. Chem., 1941, 141, 993.

12. Keys, A., and Taylor, H., The behavior of the plasma colloids in recovery from brief severe work and the question as to the permeability of the capillaries to proteins. J. Biol. Chem., 1935, 109, 55.

13. Robinson, S., and Harmon, P. M., The lactic acid mechanism and certain properties of the blood in relation to training. Am. J. Physiol., 1941, 132, 757.

14. Bay, E., Barron, E. S. G., Adams, W., Case, T., Halstead, W. C., and Ricketts, H. T., The behavior of blood lactate and pyruvate with exercise at sea level and at altitude. C. A. M. report No. 344, National Research Council, 1944.

15. Tepperman, J., Bodansky, O., and Jandorf, B. J., The effect of para-aminopropiophenone-induced methemoglobinemia on oxygenation of working muscle in human subjects. Am. J. Physiol., 1946, 146, 702. 